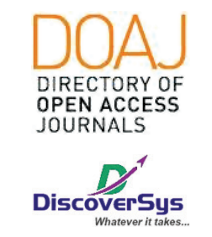

Published by DiscoverSys

\section{The correlation of upper airway abnormalities with obstructive sleep apnea syndrome in young adult}

\author{
Kanti Yunika, ${ }^{1 *}$ Febby Mardalita, ${ }^{2}$ Sefri Noventi, ${ }^{3}$ Dwi Marliyawati, \\ Muhamad Thohar Arifin ${ }^{4}$
}

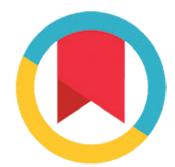

CrossMark

\title{
ABSTRACT
}

Background: Obstructive Sleep Apnea Syndrome (OSAS) is one of sleep disorder characterised by repeated episodes of total obstruction in the upper airway system during sleep. The incidence of OSAS is estimated to be $1-10 \%$ of general population. OSAS can be affected by several risk factors. One of risk factor of OSAS is upper airway abnormalities. The study aims to find out the association between individual risk factor including septum deviation, nasal turbinate hypertrophy, tonsillar hypertrophy and mallampati score with the incidence of OSAS in young adults.

Methods: Analytic observational research with case-control design was carried out on young adults aged 18-23 years in the city of Semarang during May - September 2018 grouped into OSAS and nonOSAS based on Polysomnography (PSG), then history and physical examination were performed. Statistical tests were using chi-square, Fisher's exact test, and logistic regression.

Result: Total of 22 people were included in OSAS group and 22 were included in the control group. Bivariate analysis showed septum deviation $(p=0.005)$, tonsillar hypertrophy $(p=0.015)$ and mallampati score $(p<0.001)$ significantly related to the incidence of OSAS, whereas nasal turbinate hypertrophy was not associated with OSAS incident. The results of multivariate analysis found that BMI had an OR value of 133 (95\% Cl 12.726 - 1390.002, $p<0.001$ ) independently associated with the occurrence of OSAS in young adults.

Conclusion: Septal deviation, tonsillar hypertrophy, mallampati score are the risk factors for OSAS in young adults.
'Department of Ear, Nose, Throat, Faculty of Medicine, Universitas Diponegoro

2Medical Student, Faculty of Medicine, Universitas Diponegoro

${ }^{3}$ Division of Cardiology, Faculty of Medicine, Universitas Diponegoro ${ }^{4}$ Departement of Neurosurgery, Faculty of Medicine, Universitas Diponegoro

*Correspondence to: Kanti Yunika, Department of Ear, Nose, Throat, Faculty of Medicine, Universitas Diponegoro

kantiyunika@gmail.com

Received: 2019-09-06 Accepted: 2020-07-09 Published: 2020-08-01

Keywords: OSAS, PSG, septum deviation, nasal turbinate hypertrophy, tonsillar hypertrophy, mallampati score.

Cite This Article: Yunika, K., Mardalita, F., Noventi, S., Marliyawati, D., Arifin, M.T. 2020. The correlation of upper airway abnormalities with obstructive sleep apnea syndrome in young adult. Intisari Sains Medis 11(2): 461-465. D0I: 10.15562/ism.v11i2.608

\section{INTRODUCTION}

Obstructive Sleep Apnea Syndrome (OSAS) is a form of sleep disorder characterised by blockages in the upper respiratory tract for 10 seconds or more during sleep. ${ }^{1-3}$ As the most common sleep disorder, $10 \%$ of adults in the worldwide are estimated to suffer from OSAS. ${ }^{4,5}$ The prevalence of OSAS in the general population, around $11.4 \%$ for men and $4.7 \%$ for women and is expected to increase every year. ${ }^{6}$

OSAS screening can be done using the Berlin questionnaire and the Epworth Sleepness Scale (ESS) questionnaire. ${ }^{7}$ But, the gold standard for diagnosis of OSAS can definitely use polysomnography (PSG). ${ }^{8}$ PSG is a device that can show brain electrical activity, respiration, oxygen saturation during sleep and the severity of OSAS measured by Apnea-Hypopnea Index (apnea-hypopnea index, AHI). ${ }^{9-11}$

Apart from all clinical and scientific advances regarding OSAS, most (70-90\%) people affected by OSAS remain undiagnosed. ${ }^{6}$ Lack of patient awareness, medical personnel have not received the training needed to help speed up case finding, and the high price of PSG examinations as gold OSAS standards are the cause of many undiagnosed OSAS patients. Therefore, knowledge of risk factors for
OSAS is important to direct diagnostic attention to those with the highest risk. ${ }^{4,8}$

Risk factors for OSAS include obesity, middle age, menopause in women, large neck circumference, craniofacial structural abnormalities, and upper airway structural abnormalities. ${ }^{10}$ In children, the main cause of OSAS is tonsillar and adenoid hypertrophy, which can increase airway resistance. ${ }^{12}$ Whereas in adults, OSAS is often associated with obesity. Obesity can change the volume and anatomical shape of the airways thereby reducing upper airway volume. ${ }^{13}$

Various studies have shown that there is a relationship between upper airway structure abnormalities and OSAS in children and the elderly. One of Factors that play a role in the pathogenesis of OSAS is craniofacial abnormalities ranging from the nose to the hypopharynx which can cause narrowing in the upper airway. This regional abnormality can produce high resistance. This resistance also predisposes to the collapse of the upper airway. Pharyngeal collapse is found in $81 \%$ of 64 OSA patients and $75 \%$ of them have more than one upper airway constriction. ${ }^{14}$ 
Based on the facts above, it can be seen the relationship between upper airway structure abnormalities and OSAS. In previous studies, we have not discussed the relationship of upper airway abnormalities to OSAS in young adults. The researcher was interested in seeing the relationship between upper airway abnormalities and OSAS in young adults, especially students of the Faculty of Medicine, Diponegoro University.

\section{METHOD}

The design of this study is a case control. The sample amounted to 44 people aged 18-23 years who were asked to be used as samples with written

Table 1 Characteristics of Sample

\begin{tabular}{|c|c|c|}
\hline Variable & Number & Percentage (\%) \\
\hline \multicolumn{3}{|l|}{ Diagnosis } \\
\hline OSAS & 22 & 50 \\
\hline NonOSAS & 22 & 50 \\
\hline \multicolumn{3}{|c|}{ Nasal septal deviation } \\
\hline Deviation & 17 & 38.6 \\
\hline No deviation & 27 & 61.4 \\
\hline \multicolumn{3}{|c|}{ Turbinate hypertrophy } \\
\hline Hypertrophy & 28 & 63.6 \\
\hline No hypertrophy & 16 & 36.4 \\
\hline \multicolumn{3}{|c|}{ Tonsillar hypertrophy } \\
\hline Hypertrophy & 20 & 45.5 \\
\hline No hypertrophy & 24 & 54.5 \\
\hline \multicolumn{3}{|l|}{ Mallampati score } \\
\hline Severe & 19 & 43.2 \\
\hline Mild & 25 & 56.8 \\
\hline \multicolumn{3}{|l|}{ BMI } \\
\hline Obesity & 24 & 54.5 \\
\hline No Obesity & 20 & 45.5 \\
\hline \multicolumn{3}{|l|}{ Neck circumference } \\
\hline large & 21 & 47.7 \\
\hline No Large & 23 & 52.3 \\
\hline \multicolumn{3}{|c|}{ Abdominal circumference } \\
\hline Large & 23 & 52.3 \\
\hline No Large & 21 & 47.7 \\
\hline \multicolumn{3}{|l|}{ Allergic Rhinitis } \\
\hline Yes & 9 & 20.5 \\
\hline No & 35 & 79.5 \\
\hline \multicolumn{3}{|l|}{ Gender } \\
\hline Male & 23 & 52.3 \\
\hline Female & 21 & 47.7 \\
\hline Total & 44 & 100 \\
\hline
\end{tabular}

approval. The sample consisted of 22 cases based on the results of the PSG examination was proven to be OSAS and control with the results of PSG examination showed not to have OSAS. The subjects were taken by consecutive sampling method. The tools and materials used were PSG for the OSAS gold standard headlamp, nose speculum for physical examination of the nose, tongue spatel for physical examination of the oral cavity, microtoise for measuring height bodies, digital scales to measure body weight, informed consent sheet and ISAAC questionnaire, ESS questionnaire. This study used descriptive analysis to study the demographic characteristics of each variable, then continued the bivariate Chi-square analysis to determine the relationship between the independent variables and the variables studied, and multivariate analysis to determine the most preferred independent variables with OSAS. Ethical clearance was obtained from the Ethical Committee of the Faculty of Medicine, Universitas Diponegoro with reference number: No.217/EC/FK_RSDK/IV/2018.

\section{RESULTS}

\section{Characteristics of Sample}

The table above shows that from the polysomnographic examination OSAS respondents and NonOSAS respondents were the same numbers. Based on a physical examination of the nose performed on 44 respondents, the majority of respondents did not have a septal deviation or normal (61.4\%) and had turbinate hypertrophy (63.6\%). Based on examination of the oral cavity, the majority of respondents did not have tonsillar hypertrophy or normal (54.5\%) and had a mild mallampati score $(56.8 \%)$. Based on BMI examination, the majority of respondents were obese (54.5\%) and had a majority of the neck circumference not large (52.3\%). The majority of respondents also had obese abdominal circumference (52.3\%). The majority of respondents were male (52.3) and did not suffer from allergic rhinitis (79.5\%) (Table 1).

\section{Bivariate Analysis}

From the table above it can be obtained the nasal septal deviation $(\mathrm{p}=0.005 \mathrm{OR}=6.5)$, tonsillar hypertrophy $(\mathrm{p}=0.015 ; \mathrm{OR}=4,667)$ and mallampati score $(\mathrm{p}<0.001 ; \mathrm{OR}=16,889)$ associated with the occurrence of OSAS. The confounding variables included BMI $(\mathrm{p}<0.001 ; \mathrm{OR}=133)$, neck circumference $(\mathrm{p}<0.001 ; \mathrm{OR}=28.5)$, abdominal circumference $(\mathrm{p}<0.001 ; \mathrm{OR}=63.3)$, and gender $(p=0.035 ; \quad O R=3.75) \quad$ significantly associated with the incidence of OSAS. Nasal turbinate and allergic rhinitis are not significantly associated with 
Table 2 Bivariate Analysis

\begin{tabular}{|c|c|c|c|c|}
\hline \multirow[b]{2}{*}{ Variable } & \multicolumn{2}{|c|}{ Study Group } & \multirow[b]{2}{*}{$\mathbf{P}$} & \multirow[b]{2}{*}{ OR } \\
\hline & OSAS & Non OSAS & & \\
\hline \multicolumn{5}{|c|}{ Nasal septal deviation } \\
\hline Deviation & $13(59.1 \%)$ & $4(18.2 \%)$ & $0.005^{\star}$ & 6.500 \\
\hline No deviation & $9(40.9 \%)$ & $18(81.8 \%)$ & & \\
\hline \multicolumn{5}{|l|}{ Nasal Turbinate } \\
\hline Hypertrophy & $16(72.7 \%)$ & $12(54.5 \%)$ & $0.21^{\star}$ & 2.222 \\
\hline No hypertrophy & $6(27.3 \%)$ & $10(45.5 \%)$ & & \\
\hline \multicolumn{5}{|c|}{ Tonsillar hypertrophy } \\
\hline Hypertrophy & $14(63.6 \%)$ & $6(27.3 \%)$ & $0.015^{\star}$ & 4.667 \\
\hline No hypertrophy & $8(36.4 \%)$ & $16(72.7 \%)$ & & \\
\hline \multicolumn{5}{|l|}{ Mallampati score } \\
\hline Severe & $16(72.7 \%)$ & $3(13.6 \%)$ & $<0.001^{\star}$ & 16.889 \\
\hline Mild & $6(27.3 \%)$ & $19(86.4 \%)$ & & \\
\hline \multicolumn{5}{|l|}{ BMI } \\
\hline Obesity & $21(95.5 \%)$ & $3(13.6 \%)$ & $<0.001^{\star}$ & 133 \\
\hline No Obesity & $1(4.5 \%)$ & $19(86.4 \%)$ & & \\
\hline \multicolumn{5}{|l|}{ Neck circumference } \\
\hline large & $18(81.8 \%)$ & $3(13.6 \%)$ & $<0.001^{\star}$ & 28.5 \\
\hline No Large & $4(18.2 \%)$ & $19(86.4 \%)$ & & \\
\hline \multicolumn{5}{|c|}{ Abdominal circumference } \\
\hline Large & $20(90.9 \%)$ & $3(13.6 \%)$ & $<0.001^{\star}$ & 63.33 \\
\hline No Large & $2(9.1 \%)$ & $19(86.4 \%)$ & & \\
\hline \multicolumn{5}{|l|}{ Gender } \\
\hline Male & $15(68.2 \%)$ & $4(18.2 \%)$ & $0.035^{*}$ & 3.750 \\
\hline Female & $7(31.8 \%)$ & $18(81.8 \%)$ & & \\
\hline \multicolumn{5}{|l|}{ Allergic Rhinitis } \\
\hline Yes & $6(27.3 \%)$ & $3(13.6 \%)$ & $0.457^{\#}$ & 2.375 \\
\hline No & $16(72.7 \%)$ & $19(86.4 \%)$ & & \\
\hline
\end{tabular}

${ }^{\star}$ Chi-Square test

\#Fhisher's exact test

Table 3 Homogeneity test

\begin{tabular}{lccc}
\hline Levene Statistic & df1 & df2 & p \\
\hline 4.800 & 1 & 42 & 0.034 \\
\hline
\end{tabular}

Table 3 Multivariate analysis

\begin{tabular}{llcccc}
\hline Step & Variable & B & p & OR & Cl 95\% \\
\hline 1 & BMI & 24.033 & 1 & 27378029213 & - \\
& Gender & 0.487 & 0.709 & 1.628 & $0.126-21.091$ \\
& Septal devition & 0.193 & 0.894 & 1.213 & $0.70-20.887$ \\
& Mallapati score & 0.846 & 0.657 & 2.331 & $0.56-97.442$ \\
Turbinate hypertrophy & 0.355 & 0.833 & 1.427 & $0.52-39.024$ \\
& Tonsillar hypertrophy & 0.392 & 0.754 & 1.479 & $0.127-17.190$ \\
& Neck circumference & 2.305 & 0,111 & 10,027 & $0.589-170.77$ \\
& Abdominal circumference & -21.028 & 1 & 0,001 & - \\
\hline
\end{tabular}

OSAS. It was proven by the value of $\mathrm{p}=0.21$ for nasal turbinate and $\mathrm{p}=0.457$ for allergic rhinitis (Table 2).

\section{Homogeneity Test of Nasal Turbinate Hypertrophy}

Homogeneity test it can be seen the value of $p=$ 0.034 . Because the significance is more than 0.05 , it can be concluded that the relationship of turbinate hypertrophy based on the incidence of OSAS has a different variance. Levene Statistic shows that the smaller the value, the greater the homogeneity (Table 3). The dominant risk factors for the occurrence of OSAS were proven by conducting multivariate analysis on the variable having $\mathrm{p}<0.25$.

Multivariate analysis with logistic regression tests to determine the relationship of BMI, gender, septal deviation, mallampati score, turbinate hypertrophy, tonsillar hypertrophy, neck circumference, abdominal circumference with the occurrence of OSAS, there was no significant correlation between all variable to OSAS in logistic regression model, although BMI has the highest value of odds ratio (Table 3).

\section{DISCUSSION}

OSAS prevalence increased with increasing tonsil size. The results of the bivariate analysis in this study, there was a significant relationship between tonsillar hypertrophy and the incidence of OSAS in young adults with a p-value of 0.015 . This is consistent with the study of $\mathrm{Li}$ et al. Concerning the relationship of tonsillar hypertrophy with the degree of OSAS severity in children. From a study of 35 children with an average age of 6.2 years, a $\mathrm{p}$ value $<0.0001$ was identified which indicates that tonsillar hypertrophy is associated with the degree of OSAS severity in children. ${ }^{15}$

From a study conducted by Dayyat et al. regarding the relationship between adenotonsillitis size and index number of apnea-hypopnea in non-obese OSAS patients, a $\mathrm{p}$ value $<0.0001$ indicates that adenotonsillar size is associated with the incidence of OSAS in non-obese patients. ${ }^{16}$

The results of the bivariate analysis in this study found a significant relationship between the mallampati score and OSAS in young adults $(\mathrm{p}=0,0001)$. Guerreiro et al. reported in his study that there was a significant relationship between the mallampati score and OSAS $(\mathrm{p}=0.003)$. The mallampati score was also found to be significantly correlated with the apnea-hypoapnea index in OSAS, as reported by Yuksel $(\mathrm{p}=0.001)$ and korakoc et all $(\mathrm{p}<0.001)$ in their study. ${ }^{17,18}$

The results of multivariate analysis in this study identified mallampati scores as factors associated 
with OSAS in young adults with OR values for mallampati II and IV of 3.831 (CI 95\%: 0.184$79,718)$. These results are consistent with the research conducted by Catarino et al. on truck drivers in Portugal with OR for mallampati II and IV of 3.46 (CI: 95\% 1.63-7.34). ${ }^{19}$

Tonsillar hypertrophy and severe mallapati scores are a craniofacial disorder that can reduce the size of the oropharynx and can cause narrowing of the upper airway. This regional abnormality can produce high resistance. Reduction of the size of the oropharynx causes the ability to stretch the upper airway decreases so that it tends to collapse if there is negative pressure and can increase the occurrence of OSAS. Pharyngeal collapse is found in $81 \%$ of 64 OSAS patients and $75 \%$ of them have more than one upper airway constriction. ${ }^{14}$

Based on the results of the analysis of this study, there is a significant relationship between nasal septal deviation between the incidence of OSAS with a value of $p=0.005$. This is in accordance with Kara et al. study which states that the variable anatomy of the nose (hypertension of rice concha, septal deviation of rice, internal valve and nasal externa) is associated with sleep disorders including OSAS. ${ }^{20}$

In normal individuals, the nose is a component of the airway with the greatest resistance. The presence of resistance in the upper airway plays a role in the occurrence of OSAS. The nose is not a common site of collapse in OSAS, although the resistance is large. This is because nasal patency is maintained by the structure of collagen around the nose and only minimally affected by muscle activity. ${ }^{21,22}$

The lateral wall of the pharynx is mainly composed of muscle tissue. Muscles around the pharynx can significantly affect their shape and size. Increased resistance to the nose increases negative pressure on the pharynx. So that the resistance of airflow to the channel above the pharynx causes pharyngeal collapse. ${ }^{21,22}$

Based on the results of the analysis of this study, there was no significant relationship between Turbinate hypertrophy and the incidence of OSAS in young adults with a p-value of 0.210 . Turbinate hypertrophy not related to OSAS in this study could be due to the distribution of non-homogeneous research samples $(\mathrm{p}=0.034)$. Vidigal et al. reported in his study that there was a significant relationship between inferior turbinate hypertrophy and OSAS incidence $(\mathrm{p}=0.01)$. Whereas Leitzen et al. Stated that there was a significant relationship between Turbinate hypertrophy with nasal obstruction, but Turbinate hypertrophy was not associated with OSAS. $^{23,24}$

The difference in the results of the research obtained can be because the risk factors for OSAS in patients cannot stand alone. OSAS is classified as a multifactorial disease which can be caused by various factors that can be influenced by sex, neck circumference and large abdominal circumference, obesity and upper airway disorders. According to the literature, the majority of OSAS sufferers who have obesity are also associated with Turbinate hypertrophy and high septal deviation. Abnormalities in the upper airway that collapse if the pharyngeal pressure is negative as long as inspiration exceeds the strength of the dilator muscle and abductor of the upper airway. Turbinate hypertrophy is one of the trigger factors for resistance in the airways so that the airways collapse and there is a disruption of breath flow. However, in the nasal cavity there are many other anatomical buildings that can affect the breathing process. ${ }^{25-27}$

This study analysed confounding variables namely obesity, gender, and a history of allergic rhinitis. Obesity variables assessed including criteria for body mass index, abdominal circumference and neck circumference gave a significant correlation with the incidence of OSAS, with each p-value being $p<0.001$ on body mass index, $p<0.001$ on neck circumference, $\mathrm{p}<0.001$ on the abdominal circumference. The sex indicator has a significant relationship with the incidence of OSAS in young adults with $\mathrm{p}=0.035$. The incidence of allergic rhinitis did not have a significant relationship ( $\mathrm{p}=0.457)$ with the incidence of OSAS. The results of the bivariate analysis of the criteria for BMI, abdominal circumference, neck circumference and gender were then entered into a multivariate analysis and the results showed that gender, abdominal circumference and neck circumference were not independent risk factors for OSAS. However, the results of the bivariate body mass index analysis included in the multivariate analysis revealed that body mass index was an independent risk factor for the occurrence of OSAS. This can be because the research sample in this study was mostly obese.

\section{CONCLUSION}

The conclusion of this study is that tonsillar hypertrophy is a risk factor for OSAS in young adults. 4.6 times greater than young adults who are not tonsillar hypertrophy. Rice septal deviation is a risk factor for OSAS in young adults. 6.5 times greater than young adults who do not have septal deviation. Hypertrophy of rice concha is not a risk factor for OSAS in young adults. The mallampati score is a risk factor for OSAS in young adults, 16.8 times greater than young adults with low pigeon night scores.

Suggestions for this study are, this study should be used as a basis for further research on complications that can be caused by OSAS. Future studies 
should use the gold standard for the diagnosis of allergic rhinitis, Skin Prick Test and further research on the relationship of channel abnormalities. upper breath with OSAS but in the sample not obese.

\section{FUNDING}

Current study doesn't receive any specific grant from government or any private sectors.

\section{CONFLICT OF INTEREST}

The author declares there is no conflict of interest in this study.

\section{REFERENCES}

1. Mukhlis AB. Obstructive Sleep Apnea (OSA), Obesity, Hypoventilation Syndrome (OHS) and Respiartory Distress. 2015;1(3):12-18.

2. Osman AM, Carter SG, Carberry JC, Eckert DJ. Obstructive sleep apnea: current perspectives. Nat Sci Sleep. 2018;10:21-34.

3. He L, Wang B, Lang WY, Xue J, Zhao DL, Li GF, et al. Genetically-reduced serum ACE activity might be a causal risk factor for obstructive sleep apnea syndrome: A meta-analysis. Sci Rep. 2015;5:1-9.

4. Castillo PR, Mera RM, Zambrano M, Del Brutto OH. Population-based study of facial morphology and excessive daytime somnolence. Pathophysiology. 2014;21(4):289-92.

5. Drew D, Qaddoura A, Baranchuk A. The relationship between obstructive sleep apnea and atrial fibrillation in special patient populations. Expert Rev Cardiovasc Ther. 2014;12(11):1337-48.

6. Fassbender P, Bürgener S, Haddad A, Silvanus M-T, Peters J. Perioperative incidence of airway obstructive and hypoxemic events in patients with confirmed or suspected sleep apnea - a prospective, randomized pilot study comparing propofol/remifentanil and sevoflurane/remifentanil anesthesia. BMC Anesthesiol. 2018;18(1):14-18.

7. Gonzaga C, Bertolami A, Bertolami M, Amodeo C, Calhoun D. Obstructive sleep apnea, hypertension and cardiovascular diseases. J Hum Hypertens. 2015;29(12):705-12.

8. Ishman SL, Yang CJ, Cohen AP, Benke JR, MeinzenDerr JK, Anderson RM, et al. Is the OSA-18 predictive of obstructive sleep apnea: Comparison to polysomnography. Laryngoscope. 2015;125(6):1491-5.

9. Qiao Y-X, Xiao Y. Asthma and Obstructive Sleep Apnea. Chin Med J (Engl). 2015;128(20):2798-2804.

10. Spicuzza L, Caruso D, Di Maria G. Obstructive sleep apnoea syndrome and its management. Ther Adv Chronic Dis. 2015;6(5):273-85.

11. Chen S-Y, Cherng Y-G, Lee F-P, Yeh C-C, Huang S-Y, $\mathrm{Hu}$ C-J, et al. Risk of Cerebrovascular Diseases After Uvulopalatopharyngoplasty in Patients With Obstructive Sleep Apnea. Medicine (Baltimore). 2015;94(41):e1791.

12. Tapia IE, Marcus CL, McDonough JM, Kim JY, Cornaglia MA, Xiao R, et al. Airway Resistance in Children with Obstructive Sleep Apnea Syndrome. Sleep. 2016;39(4):793-9.
13. Yuan H, Schwab RJ, Kim C, He J, Shults J, Bradford R, et al. Relationship between Body Fat Distribution and Upper Airway Dynamic Function during Sleep in Adolescents. Sleep. 2013;36(8).

14. Paul W, WC C. otolaryngology head and neck surgery. 5th ed. WF P, CW C, editors. Elsevier Ireland Ltd; 2010. $298 \mathrm{p}$.

15. A M Li, E Wong, J Kew, S Hui Tff. Use of tonsil size in the evaluation of obstructive sleep apnoea. 2002;87:156-9.

16. Dayyat R, Kheirandish-Gozal L, Capedivilla OS et al. Obstructive sleep apnea in children: relative contributions of body mass index and adenotonsillar hypertrophy. Chest. 2009;136(1):137-44.

17. Karakoc O, Akcam T, Gerek M, Genc H, Ozgen F. The Upper Airway Evaluation of Habitual Snorers and Obstructive Sleep Apnea Patients. ORL J Otorhinolaryngol Relat Spec. 2012;74(3):136-40.

18. Yuksel A. Comparison of rhinomanometry results with polysomnography and physical examination findings in patients with obstructive sleep apnea syndrome. 2014;24(4):190-4.

19. Catarino R, Spratley J, Catarino I. Sleepiness and sleep-disordered breathing in truck drivers: risk analysis of road accidents. Sleep Breath. 2013;18(1):59-68.

20. Og $\tilde{A}$, Kara M, Erdog ÃH. Evaluation of Sleep Quality in Patients With Nasal Septal Deviation via the Pittsburgh Sleep Quality Index. 2016;27(7):1738-40.

21. Michels D de S, Rodrigues A da MS, Nakanishi M, Sampaio ALL, Venosa AR. Nasal Involvement in Obstructive Sleep Apnea Syndrome. Int J Otolaryngol. 2014;2014:1-8

22. White DP, Younes MK. Obstructive Sleep Apnea. Compr Physiol. 2012;2:2541-94.

23. Leitzen KP, Brietzke SE, Lindsay RW, Leitzen KP, Brietzke SE. Correlation between Nasal Anatomy and Objective ObstructiveSleep Apnea Severity. OtolaryngologyHead and Neck Surgery. 2014;150(2):325-331.

24. Tatiana de Aguiar VidigalEmail authorFernanda Louise Martinho HaddadLuiz Carlos GregórioDalva PoyaresSérgio TufikLia Rita Azeredo Bittencourt. Subjective, anatomical, and functional nasal evaluation of patients with obstructive sleep apnea syndrome. Sleep Breath. 2013;17(1):427-433.

25. Lecube A, Sampol G, Lloberes P, Romero O, Mesa J, Morell F, et al. Asymptomatic sleep-disordered breathing in premenopausal women awaiting bariatric surgery. Obes Surg. 2010;20(4):454-61.

26. Enciso R, Shigeta Y, Nguyen M, Clark GT. Comparison of cone-beam computed tomography incidental findings between patients with moderate/severe obstructive sleep apnea and mild obstructive sleep apnea/healthy patients. Oral Surg Oral Med Oral Pathol Oral Radiol. 2012;114(3):373-81.

27. Dehghanmehr S, Shadadi H, Mansouri A, Arbabisarjou A. Effect of oral saffron capsules on sleep quality in patients with diabetes at Zabol-Iran. Bali Medical Journal. 2017;6(3):595-600. DOI:10.15562/bmj.v6i3.623

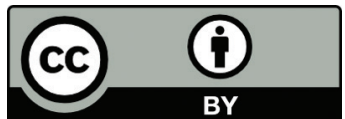

This work is licensed under a Creative Commons Attribution 